Оганьян Александр Григорьевич

кандидат экономических наук, доцент

Высшей школы управления и предпринимательства Донского государственного

технического университета

\section{ПРОБЛЕМЫ ФОРМИРОВАНИЯ ИННОВАЦИОННО ОРИЕНТИРОВАННОЙ ИНСТИТУЦИОНАЛЬНОЙ СТРУКТУРЫ СОВРЕМЕННОЙ ВЫСШЕЙ ШКОЛЫ В РОССИИ}

Аннотация:

Целью работы является исследование проблем формирования инновационно ориентированной институциональной структуры современной высшей школы в России. Исследование основывается на общенаучной методологии, которая предусматривает применение системного, институционального и эволюционного подходов к решению проблем. Рассмотрены сущность и содержательные аспекты проблемы формирования инновационно ориентированной институциональной структуры современной высшей школы в России через призму формирования и развития нового типа экономической системы, обусловливающей в качестве фундаментальной основы и стратегического инструментария реализации конкретную область общественного воспроизводства, которая в разрезе содержательных характеристик включает генерацию, распределение, перераспределение и усвоение новых знаний. Таким образом фактически воплощается индустриальный способ производства, использования и распространения производительной, трансформационной ценности нового знания, обеспечиваются интенсификация всего процесса, формирование особых условий институциональной динамики национальной экономической системы. Результаты проведенного исследования могут быть использованы в качестве концептуальной основы в процессе разработки программ и проектов инновационно ориентированного развития российской экономики. В современных условиях синергетически связанная совокупность знаний в постиндустриальной экономике общества нового типа становится не менее важной составляющей, чем традиционные сферы развитых экономических систем, в связи с чем актуализируется особая воспроизводственная роль системы высшей школы.

\section{Ключевые слова:}

инновационная экономика, высшая школа, интеллектуальный потенциал, инновационно интеллектуальный этап, инновационная трансформация, национальная экономическая система, финансирование сферы высшего образования.

\section{Oganyan Aleksandr Grigoryevich}

PhD in Economics, Associate Professor, Graduate School of Management and Entrepreneurship,

Don State Technical University

\section{PROBLEMS OF CREATING THE INNOVATION-ORIENTED INSTITUTIONAL STRUCTURE OF THE MODERN HIGHER EDUCATION SYSTEM IN RUSSIA}

Summary:

The purpose of the study is to examine the problems of creating the innovation-oriented institutional structure of the modern higher education system in Russia. The research is based on the general scientific methods that involve the system-based, institutional and evolutionary approaches to addressing issues. The nature and substantive aspects of the above-mentioned problems are reviewed through the prism of the establishment and development of a new-type economic system determining a specific area of social reproduction as a fundamental basis and a strategic tool for implementation, which implies generation, distribution, redistribution and assimilation of new knowledge. This, in fact demonstrates the industrial mode of production, use and distribution of the productive, transformational value of new knowledge, intensifies the entire process, creates the favorable environment for the institutional dynamics of the national economic system. The research findings can be used as a conceptual basis when devising programs and projects for the innovative development of the Russian economy. In the modern context, a synergistic set of knowledge in the postindustrial economy of a new-type society becomes as important as the traditional scope of the developed economic systems. Therefore, a special reproductive role of the system of higher education is updated.

Keywords innovative economy, higher education system, intellectual potential, innovative intellectual stage, innovative transformation, national economic system, investment in higher education.

Глубокий экономический и политический кризис, ознаменовавший распад Советского Союза и переход Российского государства к тяжелым 1990-м гг., серьезно дистанцировал проблемы высшего образования из области первостепенных задач и функций государства в контексте реализации государственной социально-экономической политики, направленной на интенсификацию качественных составляющих трансформационных процессов развития общества. Вторичность сфреры образования была обусловлена выходом на первый план проблем реформирования российской экономической и политической системы. 
Главная задача Правительства РФ в области реализации государственной политики высшего образования, исходя из предпринятых в тот период шагов, состояла в трансформационных преобразованиях, обеспечивающих перестройку структуры фринансирования сферы высшего образования с возможностью и допустимостью кардинального сокращения его объемов.

Реформационные преобразования системы высшей школы были отчуждены от сферы стратегических приоритетов государственной политики, что было обусловлено более важными или, точнее, определяющими проблемами переходного периода. Отсюда ключевую роль в реализации институциональных преобразований стали играть так называемые группы специальных интересов - отраслевые органы государственного управления (федеральные и региональные), общественные организации, ориентированные на протекцию интересов различных профессиональных сообществ (союзы защиты прав предпринимателей, союзы промышленников различных специализаций производства и т. п.). Важно указать, что содержательный характер и эффективность реализуемых реформационных преобразований стали определяться направленностью данных интересов и степенью силы влияния, оказываемого данными группами.

Государственные органы управления образованием были непосредственно заинтересованы в реализации таких реформационных преобразований, которые привносили системность и регулярность в функционирование бюджетного источника финансирования образования, что действительно обеспечивало его стабильность и устойчивость. В данном случае реформы позволяли установить некоторые гарантии упорядоченности поступления бюджетных ассигнований.

Реальная область интересов персонала вуза к периоду активной реализации реформационных преобразований состояла в том, чтобы изменить тренд, направленный на прогрессивные снижения их фринансового положения в сравнении с другими секторами национальной экономической системы. В связи с этим в область их интересов входили такие, которые удовлетворяли возможности формирования адекватной связи между объемами финансирования вузов и объемами материального стимулирования труда персонала, взаимоувязанными с фактическим уровнем трудозатрат в других секторах национальной экономической системы.

Трансформационные преобразования российской экономической системы выступили положительным посылом среди широкого спектра различных групп населения, что наряду с ослаблением административного давления на общественное мнение, получившее в вузах наибольшее распространение, сложно позиционировать как кардинальный сдвиг в совершенствовании механизмов функционирования системы высшей школы с позиции оценки стратегических перспектив усиления институциональной динамики отечественной высшей школы как базового фактора инновационно ориентированных трансформационных преобразований экономики России.

Однако не следует указывать исключительно на малоэффективные составляющие в числе мер государственной политики периода перестройки. Важно отметить и то, что были достигнуты некоторые положительные изменения в деятельности российской высшей школы, прежде всего связанные с появлением принципиально новых видов вузов, апробацией и массовизацией инновационных программ и технологий обучения, распространением индивидуалистических (субъектноориентированных) подходов и устранением массовой унификации высшего образования при попытке исключения «вымывания» конкурентных преимуществ и самобытных составляющих российской системы высшего образования.

Следует учесть, что положительные сдвиги в содержательных характеристиках функционирования российской системы высшей школы не были соразмерны ее существенной отсталости в части обновления материально-технической базы.

При этом в логике данного процесса присутствовали обращения к международной практике. В частности, расширение объемов государственного фринансирования прикладных исследований и тенденция к сотрудничеству между университетскими и научно-производственными комплексами отражают процесс расширения финансовых потоков со стороны бизнеса в науку и образование [1, р. 348]. Это позволяет интенсифицировать процесс институциональной динамики высшей школы.

Также следует подчеркнуть, что российская система высшей школы и непосредственно активно развивавшийся в данный период негосударственный сектор в отличие от ряда секторов национальной экономической системы фрормируют самостоятельные негосударственные высшие образовательные учреждения, что в остальных секторах предшествовало процессу приватизации государственных предприятий с соответствующей материально-технической базой.

Наиболее острым периодом для высшей школы России и образования в целом был 1994 год, когда Госкомимуществом были подготовлены ряд рабочих вариантов законопроекта «О разгосударствлении и демонополизации сферы образования». В частности, в одном из его вариантов предусматривалась приватизация учебных заведений по образцу уже апробированной программы приватизации в промышленности, но он был заблокирован Правительством РФ. В соответствии с другим сценарием предполагалась выборочная приватизация государственных учебных заведений, при которой основные фонды оставались в государственной собственности и пе- 
редавались во временное пользование вновь создаваемого учебного заведения. При этом планировался переход особых прав учредителя в части возможности самостоятельного определения направлений и форм реализации образовательной деятельности.

Очевидно, что указанный законопроект не получил положительного отклика ни у работников системы высшей школы и образования в целом, ни у соответствующих компетентных представителей органов власти, что может быть аргументировано возможным наступлением крайне негативных последствий для стабильности в социальной сфере.

Закономерным результатом общественного обсуждения указанных трансформационных преобразований выступило принятие Государственной думой РФ в 1995 г. фредерального закона «О сохранении статуса государственных и муниципальных образовательных учреждений и моратории на их приватизацию» [2], что в сущности означало государственный запрет на их приватизацию и какие-либо манипуляции с составом учредителей.

На наш взгляд, данные меры были оправданы в период наращивания агрессивного влияния рыночных механизмов хозяйствования, что преимущественно и выступило первым шагом на пути сохранения жизнеспособности и ресурсного потенциала, положенного в основу инновационно ориентированной модернизации и развития отечественной системы высшей школы в современных условиях.

Наращивание процесса институциональной динамики в контексте развития негосударственного сектора российской системы высшей школы, которое можно в полной мере позиционировать действительно как институциональные трансформационные преобразования, было нивелировано принятием в 1996 г. в новой редакции феедерального закона «Об образовании» [3], положения которого предусматривали следующее:

- распространение права на получение отсрочки от призыва на воинскую службу только на высшие учебные заведения, получившие государственную аккредитацию;

- исключение положения о праве негосударственных высших учебных заведений, получивших государственную аккредитацию, на получение бюджетного финансирования;

- исключение положения о предоставлении личного государственного образовательного кредита.

Важно, что в последующем в новой редакции федерального закона «Об образовании» преференции на получение отсрочки от армии были возвращены негосударственным вузам, однако второе положение так и не получило соответствующей законодательной реабилитации. Все это свидетельствует об отказе государства от бюджетного фринансирования процессов поддержки и развития негосударственного сектора российской высшей школы.

При этом даже с учетом столь серьезных институциональных коррективов развития негосударственного сектора российской системы высшего образования этот сектор все еще сохранил определенные потенциал и стимулы роста. Так, в частности, анализируя данные по российской системе высшего образования, отражающие прием на обучение по программам бакалавриата, специалитета, магистратуры по формам обучения (таблица 1), можно констатировать, что общее число обучающихся за исследуемый период с 2000 по 2016 г. сократилось на 12,09\%. Кроме того, в отдельные годы: 2005 г. (268,0 тыс. чел.) и 2010 г. (204,0 тыс. чел.) число поступивших в сравнении с базовым 2000 г. (152,2 тыс. чел.) годом было выше на 76,1 и 34,0 \% соответственно [4].

Таблица 1 - Прием на обучение по программам бакалавриата, специалитета, магистратуры по формам обучения за 2000-2016 гг., тыс. чел.

\begin{tabular}{|c|c|c|c|c|}
\hline \multirow{2}{*}{ Год } & \multirow{2}{*}{ Всего принято студентов } & \multicolumn{3}{|c|}{ В том числе на отделения } \\
\hline & & очные & очно-заочные (вечерние) & заочные \\
\hline 1 & 2 & 3 & 4 & 5 \\
\hline \multicolumn{5}{|c|}{ Все образовательные организации высшего образования } \\
\hline 2000 & 1292,5 & 687,5 & 81,9 & 503,4 \\
\hline 2005 & 1640,5 & 830,7 & 86,1 & 688,6 \\
\hline 2010 & 1399,5 & 659,6 & 52,4 & 672,1 \\
\hline 2011 & 1207,4 & 628,0 & 40,4 & 532,7 \\
\hline 2012 & 1298,2 & 673,4 & 40,8 & 578,4 \\
\hline 2013 & 1246,5 & 664,5 & 34,6 & 542,3 \\
\hline 2016 & 1157,8 & 674,3 & 34,4 & 449,1 \\
\hline \multicolumn{5}{|c|}{ Государственные и муниципальные образовательные организации высшего образования } \\
\hline 2000 & 1140,3 & 621,9 & 69,1 & 429,8 \\
\hline 2005 & 1372,5 & 746,4 & 66,1 & 530,2 \\
\hline 2010 & 1195,4 & 628,1 & 41,1 & 515,6 \\
\hline 2011 & 1057,7 & 604,2 & 32,9 & 418,0 \\
\hline 2012 & 1111,6 & 642,5 & 33,1 & 433,2 \\
\hline 2013 & 1066,8 & 631,1 & 28,9 & 403,7 \\
\hline
\end{tabular}


Продолжение таблицы 1

\begin{tabular}{|c|c|c|c|c|}
\hline 1 & 2 & 3 & 4 & 5 \\
\hline 2016 & 1038,2 & 650,1 & 31,4 & 356,7 \\
\hline \multicolumn{4}{|c|}{ Частные образовательные организации высшего образования } \\
\hline 2000 & 152,2 & 65,6 & 12,8 & 73,6 \\
\hline 2005 & 268,0 & 84,3 & 20,0 & 158,4 \\
\hline 2010 & 204,0 & 31,5 & 11,3 & 156,5 \\
\hline 2011 & 149,7 & 23,8 & 7,5 & 114,7 \\
\hline 2012 & 186,6 & 30,9 & 7,7 & 145,2 \\
\hline 2013 & 179,7 & 33,3 & 5,6 & 138,6 \\
\hline 2016 & 119,6 & 24,2 & 2,9 & 92,4 \\
\hline
\end{tabular}

Последующие функционирование и развитие сектора негосударственных вузов в существенной мере будут определяться уровнем качества подготовки выпускников и эфффективностью формирования научных кадров.

Таким образом, проблемы функционирования российской системы высшей школы всегда имели статус доминанты в процессах формирования общественного мнения. Текущие тенденции инновационно ориентированных трансформационных преобразований отечественной экономической системы предоставляют высшим учебным заведениям качественно новые возможности развития, позволяющие интенсифицировать процесс наращивания положительной институциональной динамики.

Указанные тенденции также определяются некоторыми ограничениями процесса наращивания положительной институциональной динамики высшей школы. В число наиболее существенных ограничений можно включить:

- дефицит финансирования ряда направлений деятельности современных российских вузов;

- нивелирование спроса со стороны потенциальных работодателей в отношении высококвалифицированных специалистов, вызванное удовлетворением потребности в данных специалистах в отношении ряда специальностей, таких как экономисты, юристы и др.;

- существенный отток заказов на подготовку научно-исследовательских разработок от государственных вузов к частным проектным институтам и бюро и др.

В связи С этим положительные итоги развития и непосредственно рефоомационные преобразования системы общественного мнения в части оценки роли высших учебных заведений в социуме позволили расширить их возможности, такие как:

- фрормирование международных интеграционных связей с целью развития эфрфективности функционирования в мировом образовательном пространстве;

- расширение автономии государственных вузов в отношении осуществления закупок для собственных нужд (для образовательных и научно-исследовательских целей);

- увеличение спектра реализуемых направлений подготовки и др.

Необходимо учитывать определенные принципы, закладываемые в процессе реализации планирования институциональных изменений в отечественной системе высшей школы, что в обобщенном виде представлено на рисунке 1 [5].

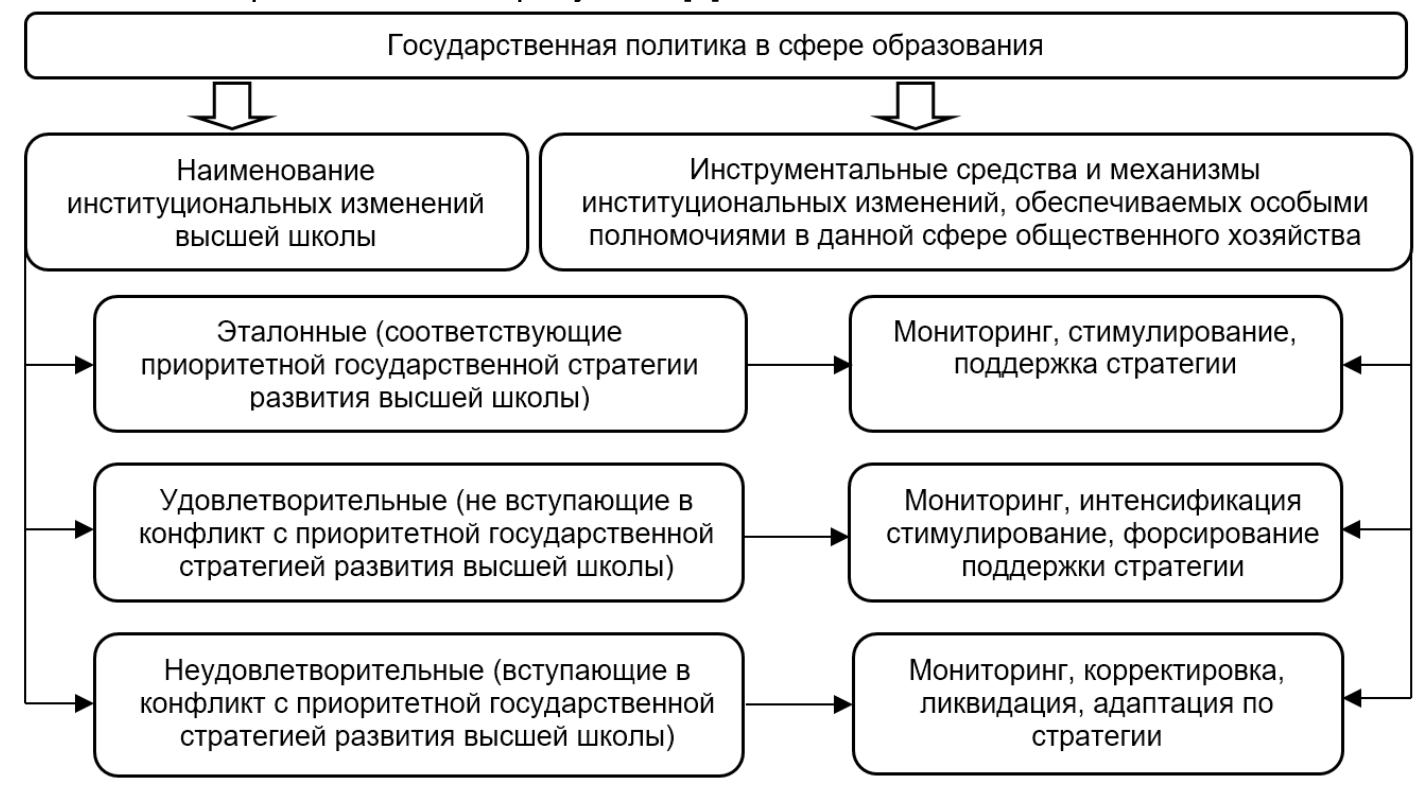

Рисунок 1 - Классификация системных механизмов институциональных изменений высшей школы 
Адаптация приведенных принципов планирования институциональных изменений российской высшей школы, реализация инновационно ориентированных механизмов и инструментальных средств, оценка эфффективности ожидаемых трансформационных преобразований, формирующих условия для оптимизации внедрения приоритетных институциональных изменений, призваны интенсифицировать процесс обновления институциональной динамики высшей школы.

Подходы к решению задач оптимизации ключевых аспектов деятельности высших учебных заведений как полноценных хозяйствующих субъектов на рынке образовательных услуг обусловливают формирование условий для укрепления стабильности в развитии как отдельного вуза, так и системы высшей школы, что закономерно окажет позитивное влияние на уровень подготовки высококвалифицированных специалистов и объективные показатели институциональной динамики высшей школы как фрактора инновационного развития национальной экономической системы.

Инновационно ориентированные трансформационные преобразования национальной экономической системы, ознаменовавшиеся на порядок более высоким уровнем интенсификации производственного процесса, и в первую очередь наукоемкого, детерминируются пропорциональным уровнем роста социально-экономического развития общества, реализуемого, с нашей точки зрения, через интенсификацию институциональной динамики высшей школы.

\section{Ссылки и примечания:}

1. Mowery D.C. The Development of Industrial Research in U.S. Manufacturing // The American Economic Review. 1990. Vol. 80, no. 2. P. $345-349$.

2. О сохранении статуса государственных и муниципальных образовательных учреждений и моратории на их приватизацию [Электронный ресурс] : федер. закон от 16 мая 1995 г. № 74-Ф3. Доступ из информ.-правового портала «Гарант».

3. О внесении изменений и дополнений в закон Российской Федерации «Об образовании» [Электронный ресурс] : фредер. закон от 13 янв. 1996 г. № 12-ФЗ. Доступ из информ.-правового портала «Гарант».

4. По данным официального сайта Федеральной службы государственной статистики (http://www.gks.ru/).

5. Рисунок 1 разработан автором. См.: Оганьян А.Г. Высшее образование как институциональный фактор интенсификации воспроизводства интеллектуального капитала в условиях инновационной трансформации российской экономической системы : монография . Ростов н/Д., 2016. 271 с.

\section{References:}

Mowery, DC 1990, 'The Development of Industrial Research in U.S. Manufacturing', The American Economic Review, vol. 80, no. 2, pp. 345-349.

Oganyan, AG 2016, Higher education as an institutional factor in intensified reproduction of intellectual capital in terms of Innovative transformation of the Russian economic system, monograph, Rostov-on-Don, 271 p., (in Russian). 